\title{
Reflection on Facilitating Learning: A One-to-One Teaching and Learning Experience
}

\author{
Antwi W. K. \\ Department of Radiography, School of Biomedical and Allied Health Sciences, University of Ghana, Accra, Ghana.
}

Email address:

wkantwi@chs.edu.gh (Antwi W. K.)

\section{To cite this article:}

Antwi W. K. Reflection on Facilitating Learning: A One-to-One Teaching and Learning Experience. Clinical Medicine Research. Special Issue: Impact of Clinical Placement on Radiography Students Ghana. Vol. 4, No. 3-1, 2015, pp. 20-24. doi: 10.11648/j.cmr.s.2015040301.15

\begin{abstract}
Reflection on an experience has been found to improve practice and therefore it is included in the interprofessional training programmes of health the professions. It improves professional expertise because it allows learning from experience. Through reflective practice the conventional way of understanding and performing a particular duty could also be given a new sense. Reflection is a way of examining practice through series of critical and creative thinking which allows one to comprehend the reasons of some actions during practice and make a move to either improve on a positive situation or correct some negative actions. This paper is a descriptive narration of a reflection on action after a piece of teaching which formed part of a fieldwork education activity.
\end{abstract}

Keywords: Reflection, Reflective Activity, Teaching Model

\section{Introduction}

Through reflection on teaching the clinical educator (who is seen in the modern context as a facilitator), is able to improve upon the required ability to perform his or her practice [1].It has been recognized that the right way to reflect is to use a reflective model which will provide guidance [2]. The four strands of Fish \& Twin [3] model of reflection which is useful for inter professional education was chosen for this teaching experience. The Fish and Twin model is not intended to be used separately but rather as a complete whole [3].

The first step of the model is the factual strand. Here the scene is set and the context of the experience described. The next step is the retrospective strand where the concern is, looking back over the whole situation and the process of practice as a whole and makes sense out of it. The third strand which is the sub-stratum which is the discovering and exploration of the assumptions, beliefs and value judgments that underlie the events and the ideas which emerged in the first two strands. The connective strand is the final step and at this level the application of the experiences of the previous levels are considered and what has been learnt from it. For the purpose of this paper the first person will be used.

\section{Factual Strand}

The session was a one to one teaching and learning experience which took place at the School of Biomedical and Allied Health Sciences in December 2013. The learner identified was a postgraduate student in physiotherapy who had complained about his difficulties in evaluating X-ray images (radiographs). This came to light during an informal interaction while discussing some issues about our respective professions. Physiotherapists do request X-ray for their patients when necessary for their treatment [4].

At times the radiographs are of poor standard and it requires training to be able to identify errors such as improper positioning of the required anatomy. Also other technical factors that affect the quality of the image which the physiotherapist needed to understand were discussed. According to Kitchie [5] the learning needs of the student or client should be identified at the beginning of any teaching session. This helps the educator to know the readiness of the learner to learn, it also shows where the student is lacking knowledge [6]. I then offered to give him some tutorials on how to evaluate and critique radiographs. We decided to use two days and each session was to take one and half hours. We scheduled the session at a period that both of us were not engaged with other activities. We then planned when and where to meet for the session. My first reaction after the interaction was to think about his needs and the way to 
proceed with the session.

\section{The Retrospective Strand}

It has been established that identification of learning needs is important because it serves as an impetus to program oneself with the necessary resources and activities that will facilitate the achievement of the required needs [7]. Similarly it enables the design of the instructional plans of the session which will address the lack of any of the three identified domains of learning (i.e., cognitive, affective and psychomotor) (Gessner) [8].

The topic to cover the learner's needs was Image Evaluation and Critique. Reece \& Walker [9] developed the Basic Teaching Model (BTM) which is a systematic approach to teaching and learning.

The sequence of the model is as follows:

- Objectives

- Entry behavior

- Instructional design and

- Assessment

This model allows the instructor and the student to become aware of the direction (objectives) of where one was going with particular attention on student's learning needs. The entry behaviour is the student's prior knowledge or what he knows about the objectives. Dent \& Harden [10] suggest that to attain the set outcomes the learner should be guided and stimulated throughout the teaching and learning process. This is to ensure that the outcome of the learning process is neither below nor too high above what the learner already knows (entry behaviour). They argue that the instructional techniques should provide the teaching process that will influence the student's learning or behaviour. One-to-one teaching has uniqueness according to Gorden [11] whose assertion is based on the premise that, one-to-one teaching;

- allows current learning needs of the student to be addressed

- promotes individuality and learning which is self directed

- enables opportunistic teaching in the sense that an opportunity exist for the teacher to adjust the teaching to suit the learning needs of the student.

Guided by this principle and the Reece \& Walker [9] teaching model, I chose to conduct one-to-one teaching of a physiotherapist. At the first day of our meeting I had gone to arrange the lecture room which was free to suite the session. I had also prepared my teaching aids which were in the form of radiographs, flip chart and overhead projector and a hand out. We exchanged greetings and, to gain his attention, I gave an overview of what we will be doing. I brought out the objectives that I had set to compare with what the student aimed to achieve. This was to promote student centered learning where the learning outcomes would not be imposed on the learner.

There were conflicting aims here. In my objectives, I included the processes of radiograph formation and the factors that can affect its quality. The student felt he did not need that because his interest was specifically centered on positioning. For example how to identify that the correct projection has been taken. I understood his point and I took time to explain to him why understanding the process of image formation is important and how it also relates to the rest of the objectives. I made the physiotherapist aware that there will be assessments as we move on with each session. This was seen as important because, based on the approach of Gorden [10] mini assessments allows the learner to identify any gaps in their learning which apart from stimulating students to utilize the new material in practice it reinforces learning and makes student's attention focused. According to Robertson et al [12] assessments also allows the teacher to evaluate the teaching itself and how well the new information has been understood or assimilated by the learner.

\section{The Sub-Stratum Strand}

Being the instructor I thought I had to be in control by giving what I felt was necessary. Having sorted out the variations in the objectives we then had common outcomes. No changes were made to my objectives because it also took care of what he (the physiotherapist) aimed to achieve. In trying to motivate students to learn, McMillan \& Forsyth [13] suggest that we should avoid the temptation of reinforcing our power as instructors or facilitators on learners. Students need direction and support which can be achieved through objectives. The need for objectives also stems from the assumption that no diagnosis can be made on teaching and learning if objectives are not specified from the beginning of a teaching session 14]. Also the ideas of Knowles [15] and Jarvis [16] on adult learning were applied. According to Knowles [15], adults are self directed and also they show the desire to learn which, coupled with their range of experiences they possess, makes student centered learning acceptable to them. Jarvis [16] suggests that to develop adult centered learning, one should also consider the socio-cultural interplay of the learner. Also his recognition of the four learning theories (the behaviorist, cognitive, humanist and social) could not be separated from each other as each seems to underpin the other, all of which enables adult learning.

This physiotherapist came from an institution where there was no Radiologist to assist in film interpretation and there was only one Radiographer who was working within two hospitals. This affected the quality of radiographs produced because of workload and little time to check the films. Having to take an adult through such a task was challenging despite the preparation I made. The teaching and learning started by considering the learning resources. The resources were radiography books on the topic, library, Internet, colleague radiographers were available for him to utilize any time.

In order to begin the session I inquired about his existing knowledge about the topic by going through his experiences with the use of radiographs. Also according to my student, during their ward rounds most of the consultants ask 
questions about radiographs of patients they examine, therefore the need to know more about it. Another issue that came up was that their undergraduate training did not go deeply into radiography. This interaction allowed me to know his understanding and the motivation to learn. I requested him to first all describe how X-rays are able to create images on films. He was able to tell me the way X-rays are produced but as to how they form the images on the film he did not know. Additionally I asked him what, in his own perspective, could affect the quality of radiographs that came to him. His answers were listed onto the flip chart. This enabled me to come to terms with his prior knowledge. I also realized that the student had rich anatomy background which was important for the film evaluation.

The first day was used to cover the processes of the formation of an image on the X-ray film and later the quality aspect. I then suggested we go to the computer laboratory to demonstrate to him a computer simulation of image formation instead of using the X-ray department. Before then in my preparatory period, I had checked and made sure of a web site that a simulation could be found. The laboratory exercise took about twenty minutes and the student became fascinated about the dynamic nature of the electrons moving from one point source to interact with a target. He saw how the x-rays which were subsequently produced passed through a patient onto a film. As the process was going on explanations were also given by me.

This visual aspect broadened his understanding of x-rays and in particular how a proportion of the radiation were changed into light to produce the images. Towne [17] believes that through computer simulation very important dimensions of simplified real world events can be highlighted. Towne further argues that simulation technologies contribute a lot to effective learning and teaching. I used the simulation to explain how quality could be affected through these processes. All along, contributions from the student received a praise or positive comments from me. The first session ended by asking the student to list again the factors that could affect image quality and try to explain how each of the factors affected the quality. This he did and was compared to the first one he gave by going back to the previous list on the flip chart. He could see the difference. He commented that he has never thought of or considered radiographs in that way which to me was a positive feedback. It showed that constructive learning has taken place. The session ended and I thanked and also informed him of what was to be done the next day - film critique and evaluation.

The next session which was on film critique and evaluation started the same time the next day as planned. I went over the previous study to prepare us for what we have decided for the day in a summary. I then continued with the general concept of film critique and the activities we will be carrying out. Cotton [18] on learning strategies suggested that beginning a lecture or teaching with a general principle, gives the listener, an overview of what is to be done. This provides a framework of the subject content so as to arrive at clear conclusions [8]. Interestingly, I found that the student also brought some radiographs to augment what I have already provided. This self motivation by the student impressed me a behavior which brought me to the work of Wallace [19] who asserted that when learners are allowed to identify their learning needs they initiate activities and seek the means to address them. That is, they achieve their goals by becoming responsible to their learning. Having gone through the critique exercise, other films of varying quality were given to him to critique and evaluate as final assessment. A good critiquing was done and his confidence to examine films and discuss them was better than previously a testimony that learning has taken place. Sheahan [20] identified that being able to do what previously one could not do after undergoing a learning process, implies knowledge has been built.

Before parting I gave a general overview of what we have done so far and allowed him time to reflect and also give his comments through an evaluation form I gave him. This was done to fulfill the assumptions made previously that once objectives are specified, effective evaluation of teaching and learning becomes possible. Also, giving the general overview and allowing student time to reflect supports the suggestions of Dent \& Harden [10]. They are of the view that giving learners the opportunity to reflect on a session after an overview helps them to refine what they have learnt and how it is going to be applied in the real life situation. This approach (which they call schema refining), also allows the learner to identify knowledge constructed. I gave him hand outs for the session as a guide for future learning. We exchanged compliments and parted.

Reflecting on this work I realized that by discussing the needs of the learner with him, and providing the means to achieve them, a humanistic approach to learning was in play. There was mutual respect throughout the session and any perceived need that was identified was addressed. Also by using the Reece \& Walker [9] model for teaching, the role of the teacher in a teaching episode was demonstrated in accordance with Gagne's behavioral sequence of teaching and learning. His systematic approach suggests that educational or learning goals should be specified. However, this was modified to the humanistic view of learning where student is involved in the setting of objectives making the whole teaching and learning student centered.

The entry behavior level of the model required the cognitive recall of previous knowledge which played a vital role throughout the session. Howe [21] in his work on psychology and teaching commented that the acquisition of new knowledge or information in any learning situation is enhanced when the new material relates what is already known. Learning therefore becomes meaningful he continues when the information could be transferred to real life situation or in ones practice. However, in agreement with Hulse [22] the theory of teaching and learning is complex and contradictory. Each theory underpins one another in most situations whilst in other areas there are contradictions. For example, the case of Bruner [23] and Ausubel [24] illustrates the contradictions within the cognitive camp. These two 
theorists disagree about the form that cognitive structure and material organization should be. Whilst Bruner suggest a sequence arrangement of facts, from specific to general, Ausubel's [24] idea is the opposite.

Despite the various disagreements and conflicting issues, each theorist ideas are applicable in one way or the other in the caring professions. In particular, the strict behaviorist approach to learning is useful to the psychomotor skills training in radiography [25]. He further states that like most health professionals radiographers require cognitive recall of classroom theory of anatomy to position their patients. Also a radiographer acting on request forms obeys the stimulus response theory of the behaviorist.

\section{Connective Strand}

This teaching, from the feedback of the student, showed that he gained the following knowledge: How images are formed by X-rays, the way the process that initiate formation could affect the quality of the image and how to evaluate and critique them. Also supported by his knowledge in anatomy he could distinguish between poor positioning of body part and a good one looking at the image. He also realized that it will require deeper learning using the resources available to acquire more knowledge. According to Moon,[26] deeper learning is intentional comprehension of ideas by linking new information to old knowledge and experience, as against treating new information as unrelated bits of knowledge in a surface approach to learning.

My own evaluation of the teaching and the student's feedback showed that there was too much technical jargon which I need to avoid in any teaching involving a novice in the future. Moreover, his feedback during the session contributed to its progress. Gray [27] believes that when students are actively involved in the content and process of teaching and learning, they share in the enthusiasm and excitement of a good learning and contribute suggestions which improve teaching strategy. It was helpful that the oneto-one teaching on some occasions became more of discussions though I could not avoid being didactic at some point of the sessions which $\mathrm{i}$ need to correct in future situations to make the teaching more student centered. There were questions that I could have easily allowed the student find by himself from the resources available. It also brought my attention to group learning where contributions from other students would have enriched the session. Literature indicates that although groups are usually able to solve problems more effectively than a single member, groups rarely do as well as their best member could do alone [28]. However, in this case, it was difficult to know whether this physiotherapist was better than the rest who were not included.

Through this teaching and reflective experience, I have come to understand the various theories that underpin teaching and learning and their application in radiography practice. I also gained an experience in the management of unexpected and unplanned incidents that can occur. The differing objectives is an example of this incident. I have gained an insight into skills required for lesson planning, such as devising aims and learning outcomes, selecting content and the systematic way of preparing classroom material.

I developed important teaching skills including introducing a topic, assessing or questioning and improving the studentteacher interaction. Moreover, the skill needed to assess and provide feedback was also enhanced. In addition, the use of varied styles of instructional design, have helped me to understand the importance of creative teaching strategies such as the use of computer technology. This reflective experience has enhanced my understanding of Davis [29] that reflection leads to better learning and also challenges us as practitioners in the way we think and feel and believes [30].

\section{Conclusion}

In conclusion, following the feedback and reflection on the whole process three themes emerged. These are the benefits and usefulness of the session, the experience itself and suggestions for improving the use of the strategy in my future programmes. However this might involve a bigger group.

\section{References}

[1] Scalan J.M and Chernomas W.M. (1997) Developing the reflective teacher. Journal of Advanced Nursing 25 (6): 11381143 .

[2] Johns C. (2000) Becoming a Reflective Practitioner. A reflective and holistic approach to clinical nursing. Practice development and clinical supervision. Oxford: Blackwell Science.

[3] Fish D and Twinn S. (1997) Quality Clinical Supervision in the Health Care Professions : Principled approaches to practice. Oxford: Butterworth Heinemann.

[4] Espeland A and Baerheim A. (2003) Factors affecting practitioners' decision about plain radiography for back pain: implications for classification of guideline barriers - a qualitative study. BMJ Health Services Research 3(8). [PubMed].

[5] Kitchie S. (2003) Determinants of learning. In- Nurse as Educator: Principles of teaching andlearning [Bastabel B.S. (ed)]. London. Jones and Bartlett.

[6] Hinchliff S. (1992) The Practitioner as Teacher. London: Scutari Press.

[7] Wharrad H., Clifford C., Horsburgh M et al. (2003) Global networks explores diversity and opportunity in nurse education. Nurse Education Today 22 (10): 15-23.

[8] Gessner B. (1998) Adult Education: The corner stone of patient education. Nursing Clinics ofNorth America 24 (3): 589-595.

[9] Reece I and Walker S. (2000) Teaching, Training and Learning. Sunderland: Business Education. 
[10] Dent A.J and Harden R.M. (2001) A Practical Guide for Medical Teachers. Edinburgh: Churchill Livingstone.

[11] Gordon J. (2003) One-to one teaching and feedback. In Cantillon P., Hutchinson L and Wood D (eds) $A B C$ of Learning and Teaching in Medicine. London: BMJ Publications.

[12] Robertson S., Rosenthal J and Dawson V. (1997) Using assessment to promote student learning. In McAllister L., McLeod S., Lincoln M and Maloney D. (eds) Facilitating Learning in Clinical Settings. London: Stanley Thornes.

[13] McMillan J.H and Forsyth D.R. (1991) "What theories of motivation say about why learners learn." In-Menges R.J and Svinicki M.D (eds) College Teaching: From theory to Practice. New directions for teaching and learning, number 45. San Franciosco:Jossey-Bass.

[14] Gronlund N.E. (1981) Measuring and Evaluating Teaching. New York: Macmillan.15. Knowles M. (1984) The Adult Learner: a neglected species. Houston: Gulf Publishing.

[15] Jarvis P. (1995) Adult and continuing Education. London: Routledge

[16] Towne D.M. (1995) Learning and Instructions in Simulation environments. Eaglewood Cliffs: Educational Technology Publications.

[17] Cotton J. (1995) The theory of learning strategies. An introduction. London: Kogan Press.

[18] Wallace M. (1999) Life Long Learning. Edinburgh: Churchill Livingstone.

[19] Welsh I and Swann C. (2002) Partners in Learning. A guide to support and assessment in nurse education. Oxon: Radcliffes Medical Press.
[20] Sheahan J. (1980) Some aspects of the teaching and learning of nursing. Journal of Advanced Nursing 5(5): 491-511

[21] Howe M.J.A. (1984) A Teachers' Guide to the Psychology of Learning. Oxford: Basil Blackwell.

[22] Hulse S.F. (1992) Learning theories: Something for everyone. Radiologic Technology 63(3): 198-202.

[23] Bruner J. (1996) The Culture of Education. Cambridge: Harvard University Press.

[24] Ausubel D.P. (1978) Educational psychology: a cognitive view. London: Holt-Rinehart and Winstone.

[25] Roger S.F. (1982) How to link theory and practice in training courses. Radiography 48 (567): 47-64.

[26] Moon J.A. (2002) Reflection in Learning and Professional Development. Theory and practice. London: Kogan Page.

[27] Gray M.T. (2003) Generating critical thinking in the classroom. Nurse Educator 28 (3): 136-140.

[28] Huczynski A.A and Bucanan D.A. (1991) Organizational Behaviour. An introductory text. New York: Prentice Hall.

[29] Davis M. (2003) Barriers to Reflective Practice. The changing nature of education. In-ActiveLearning to Higher Education. London: Sage.

[30] Burnard P (1989) Developing critical ability in nurse education. Nurse Education Today 9(4): 271-275. 